\title{
Mexico City land subsidence in 2014-2015 with Sentinel-1 IW TOPS: results using the Intermittent SBAS (ISBAS) technique
}

\author{
ANDREW SOWTER ${ }^{1 *}$, MOH. CHE AMAT ${ }^{1}$, FRANCESCA CIGNA ${ }^{2}$, STUART $^{2}$ \\ MARSH $^{1}$, AHMED ATHAB $^{1}$, LUBNA ALSHAMMARI ${ }^{1}$ \\ ${ }^{1}$ Nottingham Geospatial Institute, University of Nottingham, Nottingham NG7 2TU, \\ UK \\ ${ }^{2}$ British Geological Survey, Nicker Hill, Keyworth, Nottingham NG12 5GG, UK \\ "Corresponding author
}

\begin{abstract}
Differential Interferometric Synthetic Aperture Radar (DInSAR) can be considered as an efficient and cost effective technique for monitoring land subsidence due to its large spatial coverage and high accuracy provided. The recent commissioning of the first Sentinel-1 satellite offers improved support to operational surveys using DInSAR due to regular observations from a wide-area product. In this paper we show the results of an intermittent small-baseline subset (ISBAS) time-series analysis of 18 Interferometric Wide swath (IW) products of a $39,000 \mathrm{~km}^{2}$ area of Mexico acquired between 3 October 2014 and 7 May 2015 using the Terrain Observation with Progressive Scans in azimuth (TOPS) imaging mode. The ISBAS processing was based upon the analysis of 143 small-baseline differential interferograms. After the debursting, merging and deramping steps necessary to process Sentinel-1 IW products, the method followed a standard approach to the DInSAR analysis. The Sentinel-1 ISBAS results confirm the magnitude and extent of the deformation that was observed in Mexico City, Chalco, Ciudad Nezahualcóyotl and Iztapalapa by other C-band and L-band DInSAR studies during the 1990s and 2000s. Subsidence velocities from the Sentinel-1 analysis are, in places, in excess of $-24 \mathrm{~cm} /$ year along the satellite line-ofsight, equivalent to over $\sim-40 \mathrm{~cm} /$ year vertical rates. This paper demonstrates the potential of Sentinel-1 IW TOPS imagery to support wide-area DInSAR surveys over what is a very large and diverse area in terms of land cover and topography.
\end{abstract}

\section{Keywords}

SAR, InSAR, Sentinel-1, land subsidence, TOPS. 


\section{Introduction}

High-precision mapping of land subsidence can be achieved using satellite-based techniques, the most common of which is differential interferometric synthetic aperture radar (DInSAR) (e.g. Massonnet and Feigl, 1998). These techniques are primarily based upon the analysis of pairs of synthetic aperture radar (SAR) images that are able to identify sub-centimetre changes in the line-of-sight (LOS) position of targets. Unfortunately, such pairs are also affected by atmospheric delay and changes in the scattering behaviour between image dates that will obscure more subtle changes in position. For certain classes of deformation, such as slow monotonic motion, it is possible to determine target velocity assuming that atmospheric delay is random over time. This is the basic principle behind the two most common time-series InSAR methods used: persistent scatterer interferometry (PSI) (e.g. Ferretti et al., 2001) and the small baseline subset (SBAS) method (e.g. Berardino et al., 2002). These are based upon the time-series analysis of a stack of DInSAR observations of the deformation gathered over time. On the whole, these techniques can typically produce very accurate temporal deformation profiles for urban or rocky, sparsely vegetated areas but fail to give sufficient monitoring targets in rural settings (Crosetto et al., 2010). A recent paper by Osmanoğlu et al. (2015) compared the PSI, SBAS, SqueeSAR $^{\mathrm{TM}}$ (Ferretti et al., 2011) and StaMPS (Hooper et al., 2004; Hooper, 2008) techniques over the Mexico City area and also concluded that none of the methods were able to obtain deformation rates over agricultural farmlands and natural vegetation. A more recent attempt to extend a DInSAR analysis into rural classes is the Intermittent SBAS (ISBAS) (Sowter et al., 2013; Bateson et al., 2015) technique which appears particularly well-suited to low-resolution, wide-area deformation monitoring over a broad range of land classes, including grasslands, agricultural and forested cover (Cigna et al., 2014).

The recently-launched Sentinel-1A satellite (ESA, 2014a) provides continuity of C-band SAR all-weather and day-and-night imagery after the ERS-1/2 and ENVISAT missions and offers many benefits for the monitoring of land motion phenomena. Rapid deformation rates can be monitored due to the short repeat cycle of only 12 days of each satellite of the Sentinel-1 mission (Torres et al., 2012). With two satellites in constellation as planned, it is expected that this repeat cycle will be reduced to 6 days, particularly over Europe and Canada (Rucci et al. 2012). A consequence of this is that it will take a much shorter time to gather a significant stack of images (De Zan et al., 2008; Attema et al., 2010) which will be helpful for routine long-term monitoring applications. Furthermore, the swath width of the Interferometric Wide (IW) product is around $250 \mathrm{~km}$, allowing the monitoring of large areas using much fewer acquisitions. A short revisit time and a large swath width alone mean that Sentinel-1 IW products are able to provide a very high level of support to operational, routine land monitoring applications.

Sentinel-1 IW data is gathered using the novel Terrain Observation with Progressive Scans in azimuth (TOPS) SAR imaging technique (Holzner and Bamler, 2002; Torres et al., 2012) which offers several challenges to the design of an interferometric processing chain, primarily in terms of the preparation of the individual images and their subsequent coregistration. The coregistration accuracy requirement for Sentinel-1 TOPS InSAR processing, at one thousandth of one pixel (De Zan et al., 2014), is much more stringent than the InSAR processing requirements for stripmap products and therefore has the highest impact upon the design of a processing chain. In this paper, we shall address the possibility of generating a 
Sentinel-1 TOPS InSAR product with only minimal changes to an existing stripmap processing chain and without implementing any changes to a standard amplitude image coregistration procedure. Indeed, the proposed method could be applied to any existing stripmap InSAR processing chain.

Mexico City has one of the highest subsidence rates ever recorded, with a maximum velocity of more than $-35 \mathrm{~cm} /$ year observed in some sectors of its metropolitan area during the 1990s and 2000s (Strozzi et al., 2003; Cabral-Cano et al., 2008). This phenomenon was first observed in 1925, based upon observations from two precise levelling campaigns carried out in 1877 and 1924 (Figueroa Vega, 1976). It was subsequently concluded that the subsidence is the result of extensive groundwater extraction for domestic, industrial and municipal uses (Figueroa Vega, 1976). Numerous publications can be found on the use of multi-temporal DInSAR for monitoring land subsidence in Mexico City using C-band and L-band imagery, such as demonstrated by López-Quiroz et al. (2009), Cabral-Cano et al. (2010), Cigna et al. (2011), Osmanoğlu et al. (2011), Yan et al. (2012) and Chaussard et al. (2014). In preparation for the Sentinel-1 mission, the city was also included as a case study for the Sentinel-1 like RADARSAT-2 TOPS campaign in 2013, and several Sentinel-1 DInSAR trials were carried out by the InSAR community (e.g., ESA, 2014d; Geudtner, 2014; Lanari et al., 2015). In this paper, we join this international effort by demonstrating the derivation of wide area LOS velocities for an area encompassing Mexico City using 18 Sentinel-1A images acquired between 13 October 2014 and 7 May 2015. We compare the estimated subsidence rates with historical C-band and Lband PSI and SBAS studies, and more recent RADARSAT-2 and Sentinel-1 results from the currently available literature.

In a similar fashion to Osmanoğlu et al. (2015), we will assume a linear model for Mexico City deformation throughout this paper.

\section{The ISBAS Processing Chain}

The linear ISBAS algorithm (Sowter et al., 2013; Bateson et al., 2015; Cigna et al., 2014) is very similar in structure to the linear SBAS algorithm outlined by Berardino et al. (2002). The premise is that, from a stack of many SAR observations, a large number of low-resolution two-pass differential interferograms are generated, satisfying a threshold that primarily relates to a low orbital baseline. The phase of pixels that are of a consistently high coherence throughout the stack are then examined through regression analysis to estimate linear velocity and a height correction for the digital elevation model (DEM) used for the two-pass interferometry.

For zero-Doppler stripmap products from satellite missions such as ERS, ENVISAT, RADARSAT, TerraSAR-X and COSMO-SkyMed, the ISBAS processing follows almost exactly the same path as an SBAS algorithm but has a slightly different approach to identifying those pixels for which velocity and height correction are derived, the main difference being to relax the threshold that the pixel must display consistently high coherence over all interferograms.

\section{Sentinel-1 Interferometric Wide Products}

Sentinel-1 is the first of a family of satellites developed by the European Space Agency (ESA) specifically for the operational needs of the Copernicus programme, 
headed by the European Commission (EC), which aims to provide information to improve environmental management, climate change and civil security (http://www.copernicus.eu/). The Sentinel-1 mission is actually comprised of two satellites: Sentinel-1A was launched on 3 April 2014; and Sentinel-1B is planned for launch in early 2016. Both satellites will be placed in a near-polar, sun-synchronous orbit at an altitude of approximately $693 \mathrm{~km}$. The main instrument is a C-band SAR operating at $5.405 \mathrm{GHz}$. As mentioned above, the repeat period for a single satellite is 12 days whereas, once the second satellite is in orbit, this will decrease to 6 days.

Sentinel-1 IW Single Look Complex (SLC) products are used in this study and the basic specifications for these are shown in table 1.

Table 1. Properties of Sentinel-1 Interferometric Wide (IW) Single Look Complex (SLC) products (ESA, 2013).

\begin{tabular}{|l|l|}
\hline Spatial Resolution & $5 \mathrm{~m}$ (ground range) $\times 20 \mathrm{~m}$ (azimuth) \\
\hline Pixel Spacing & $2.3 \mathrm{~m}$ (slant range) $\mathrm{x} 14.1 \mathrm{~m}$ (azimuth) \\
\hline Incidence Angle & $29^{\circ}-46^{\circ}$ \\
\hline Polarisations & $\mathrm{HH}+\mathrm{HV}, \mathrm{VH}+\mathrm{VV}, \mathrm{HH}, \mathrm{VV}$ \\
\hline Total Swath Width & $250 \mathrm{~km}$ \\
\hline
\end{tabular}

The level-1 IW SLC product is provided as three separate sub-swaths. Each subswath consists of a series of bursts where each burst has been processed as a separate SLC image. Each burst is included, in azimuth time order, into the sub-swath with black-fill demarcation in-between.

To create a wide-area IW product from the three sub-swaths supplied, two separate processes need to be applied in order (ESA, 2013):

i. Debursting. This process concatenates the individual bursts from one subswath together into a single deburst sub-swath where the azimuth line spacing is constant from start to end and there is no black-line demarcation between sub-sequent bursts.

ii. Merging. After debursting has been applied to each of the three sub-swaths (i.e. IW1, IW2 and IW3), the sub-swaths should be mosaicked into a single wide-swath product where range column spacing is constant from near to far and the sub-swaths are aligned in azimuth.

The process of mosaicking bursts from three different swaths is illustrated in figure 1 .

For Sentinel-1 IW SLC products, the lines and columns of the bursts and subswaths have all been resampled to a common pixel spacing grid. This means that the debursting and merging may be accomplished by shifting sub-images around in integer numbers of rows and columns only and therefore no resampling of the original pixel values is necessary to form the wide area product. 
(a)

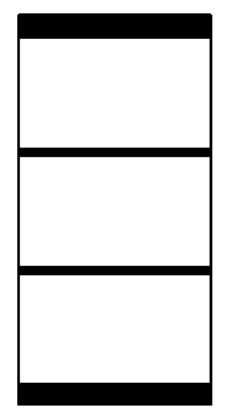

(b)

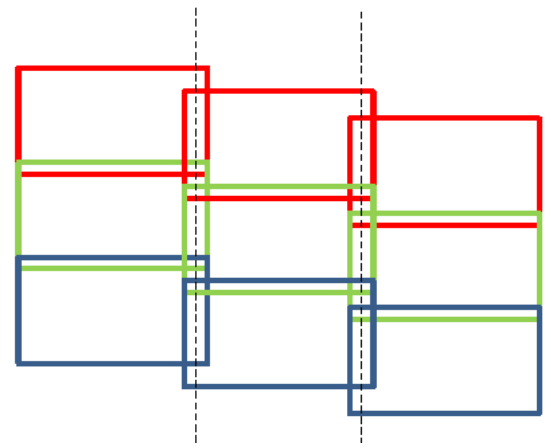

(c)

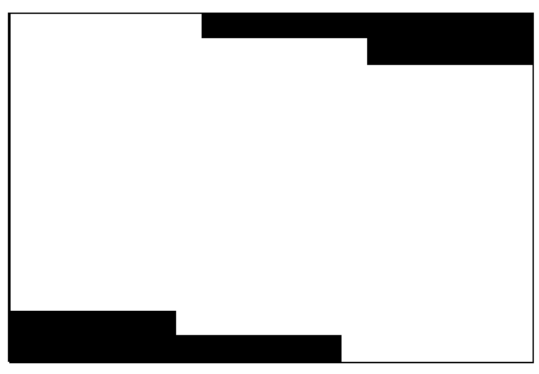

Figure 1. (a) The arrangement of bursts in an IW sub-swath. (b) Sentinel-1 burst structure with small overlaps between bursts and sub-swaths. (c) Mosaic for a full Sentinel-1 Interferometric Wide Swath consisting of 3 subswaths with 3 bursts each. After Wegmuller et al. (2015).

Another characteristic of Sentinel-1 TOPS SAR data is that the phase of a product changes rapidly in azimuth and may not easily be resampled as the phase difference between adjacent pixels can be ambiguous. This is a well-known effect and may be solved through first subtracting a simulation of the rapidly-varying azimuth phase (deramping), resampling the remainder and finally adding back the simulated phase (re-ramping). For Sentinel-1 data, the deramping function is known (ESA, 2015a).

The remaining major difference between Sentinel-1 TOPS data and stripmap data is that the any imprecision of less than one thousandth of one pixel in co-registration (e.g. equivalent to $2 \mathrm{~cm}$ in azimuth) may result in noticeable phase ramps on individual bursts (De Zan et al., 2014). Although difficult to achieve through typical convolution methods, higher levels of accuracy may be achieved through, for example, a spectral diversity technique (Scheiber and Moreira, 2000), as implemented by some authors (e.g., Lanari et al., 2015; Wegmüller et al., 2015). The spectral diversity method normally requires the analysis of the forward- and backward-looking phases in burst overlap regions caused by the squint difference. This is already more computationally intensive than the simple amplitude correlation methods more commonly used for stripmap products. Furthermore, to achieve the highest phase precision, it must be applied to every interferometric pair, which adds considerably to the processing effort. For example, for $\mathrm{N}$ stripmap products, only $\mathrm{N}-1$ pairs normally require to be coregistered; for a multiple-master algorithm, such as SBAS, this would increase many times as the number of pairs is much larger than $\mathrm{N}-1$, depending upon the baseline and temporal thresholds applied.

\section{Modification of the ISBAS Processing Chain}

The approach adopted in this paper was to make targeted changes to the existing ISBAS processing chain in order to adapt to Sentinel-1 IW products. We therefore applied the following changes: 
i. The IW SLC products were each fully deburst and merged prior to ISBAS processing. This allowed the subsequent ISBAS algorithm to treat each widearea mosaicked product as a single zero-Doppler SLC image in exactly the same manner as any zero-Doppler stripmap SAR product.

ii. The deramping function was applied to the resampling of all slave images.

We did not apply any adaptation of the ISBAS algorithm to address the requirement for high-precision coregistration primarily due to the impact this would have upon the computational effort required. As the ISBAS method performs a timeseries analysis of a large stack of interferograms, we considered that the phase ramps generated with our matching algorithm would be small in amplitude, less than one single cycle of phase, and would also be random from interferogram to interferogram, in which case this would not affect the least-squares regression analysis applied to derive the velocities.

The final ISBAS processing chain applied here to process Sentinel-1 data is shown in figure 2 in comparison with the ISBAS processing chain for stripmap data. As is clear, the main difference between the two is the addition of two additional activities relating to deburst and merging and deramping in the Sentinel-1 case.

It now remains to apply this modified algorithm to a stack of Sentinel-1 images to ascertain if it is appropriate for the derivation of pixel velocities.

(a)

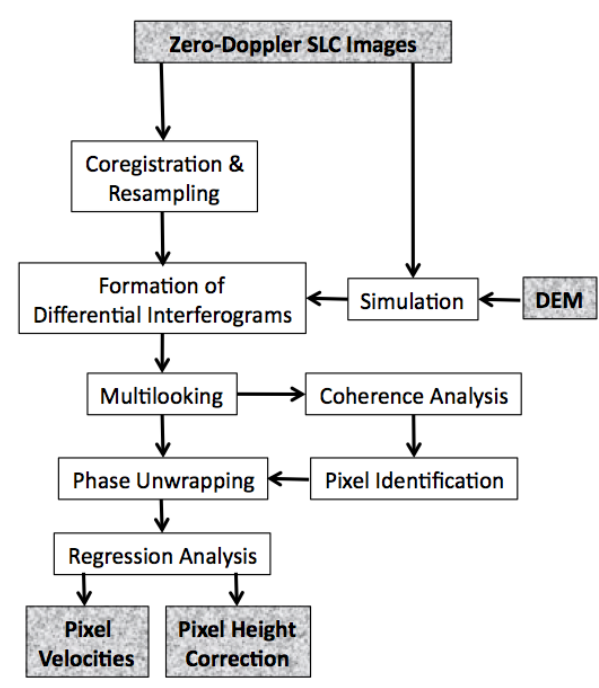

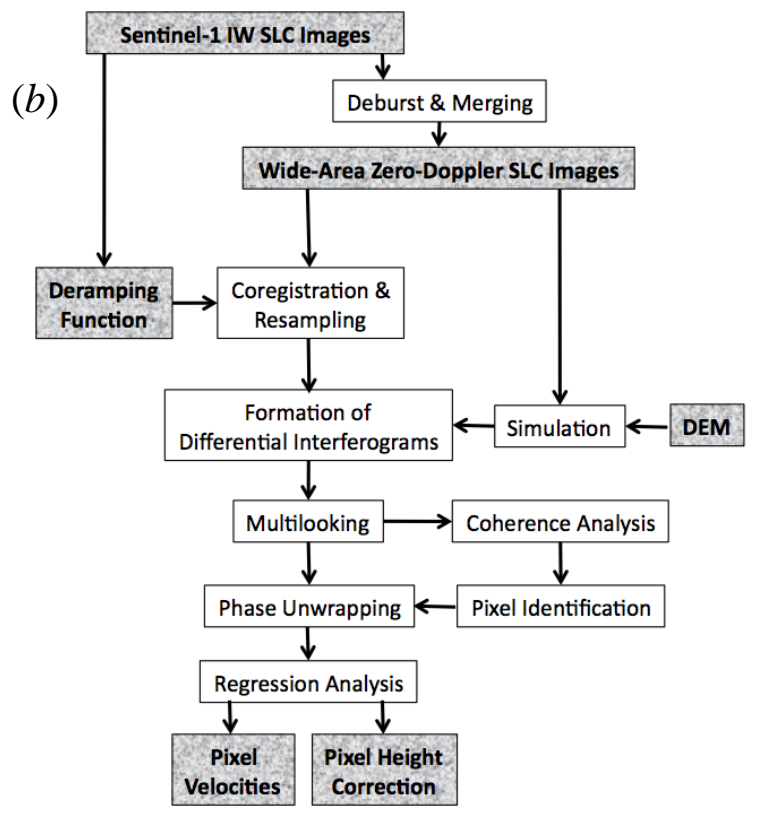

Figure 2. (a) The ISBAS processing chain as applied to stripmap SAR products and (b) the ISBAS processing chain as applied to Sentinel-1 IW SLC products (right). Note that the two only differ by the addition of deburst and merge and deramping steps to the Sentinel-1 case.

\section{The Study Area}

The area for this study is determined by the 38,588 square kilometer footprint of the Sentinel-1A images used in the analysis, located in the Central Highlands of Mexico between the Sierra Madre del Sur and the Sierra Madre Oriental (see figure 3). The 
IW scene contains Mexico City itself in the west and the area stretching some $200 \mathrm{~km}$ east of the city, which includes the city of Puebla. The average elevation for the scene is around 2,000 $\mathrm{m}$ a.s.l. but contains mountains and volcanoes that can rise above $5,000 \mathrm{~m}$. The location also lies within the Trans-Mexican Volcanic Belt and contains some significant volcanoes such as Popecatépeti, Iztaccíhuati and, on the eastern edge of the site, Pico de Orizaba. A map of the topography is also shown in figure 3, derived from SRTM data (Farr et al., 2007).

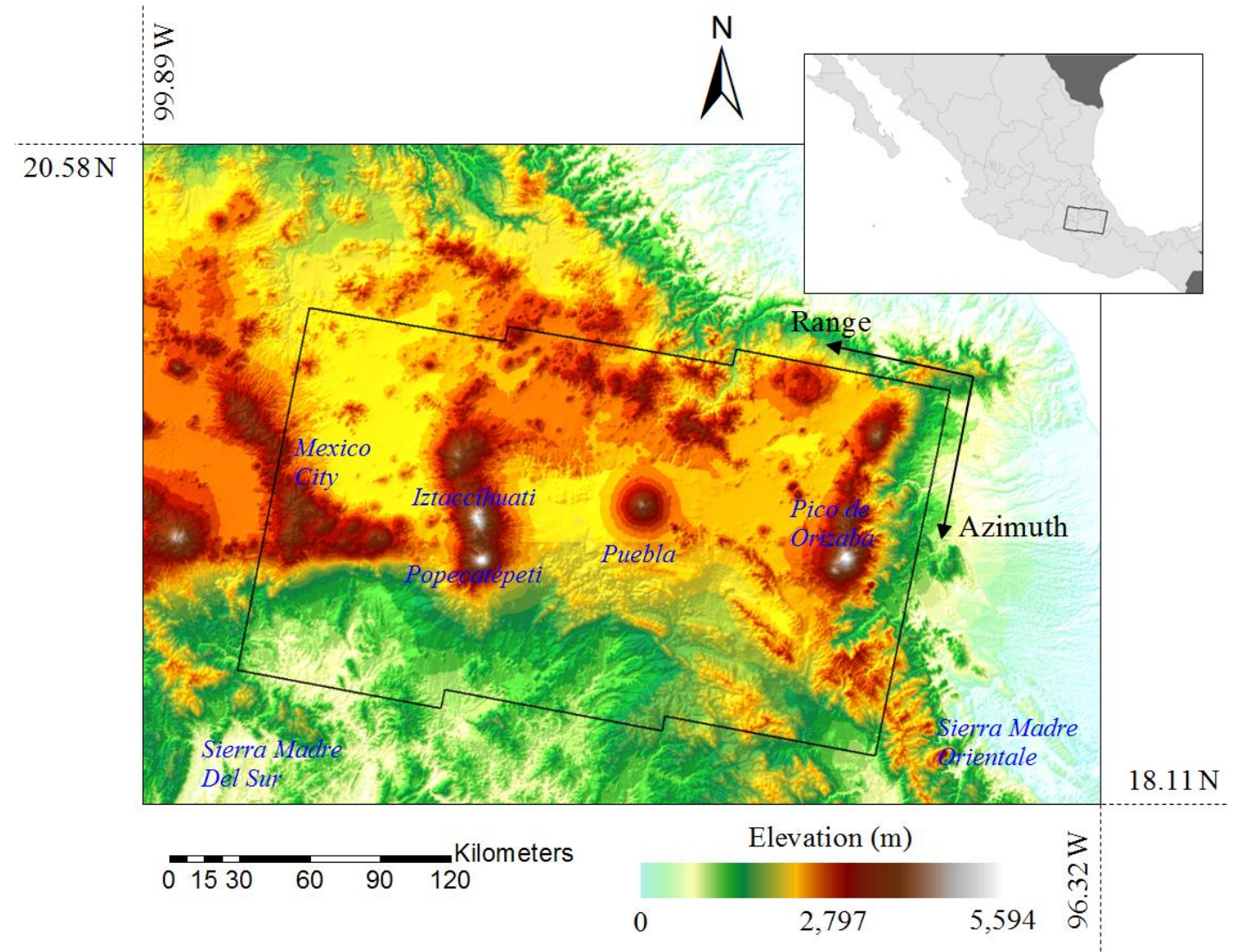

Figure 3. A map showing the elevation of the area of interest and the extent of the descending orbit Sentinel-1 frame used in this project (black line). Range (across track) and azimuth (along track) directions for the frame are indicated. A detail showing the frame location is in the top right.

Much of the area is dominated by a semi-arid climate with a colder climate around the mountain peaks. As may be seen from the land cover classes shown in figure 4, the lowland areas comprise mainly agricultural cropland, with forests dominating in the mountainous areas. 


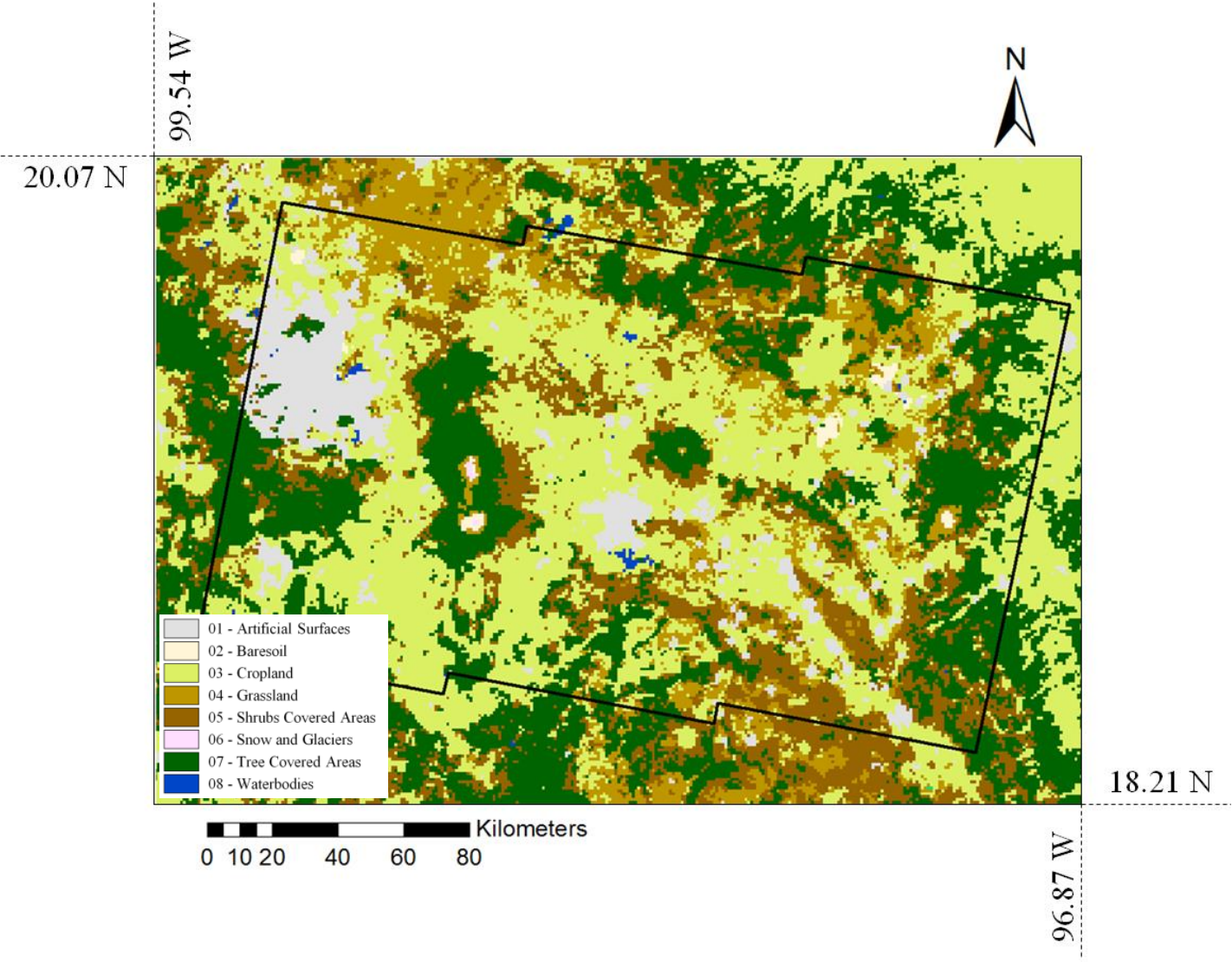

Figure 4. Land cover map of the area surveyed using Sentinel-1. Figure adapted from the FAO Global Land Cover (GLC-SHARE) Beta-Release 1.0 Database, Land and Water Division, John Latham, Renato Cumani, Ilaria Rosati and Mario Bloise, 2014: http://www.fao.org/geonetwork/srv/en/main.home (last accessed 28 July 2015), (C) FAO \& NASA.

\section{Methodology}

\subsection{Satellite Images}

We used 18 Sentinel-1A IW SLC SAR images acquired in descending passes from 3 October 2014 to 7 May 2015 for our study, listed in table 2 along with the perpendicular baseline of the orbit relative to the first image. The level-1 images were downloaded from the Sentinel-1 Scientific Data Hub (ESA, 2014c). All of the images used are in VV polarisation mode. Incidence angles across the IW swath vary from $31^{\circ}$ in near range to $46^{\circ}$ in far range. Figure 5 shows the amplitude of the first image (3 October 2014), orthorectified into a UTM frame. Note that no radiometric calibration is applied at any stage during the processing. 
Table 2. Sentinel-1 IW image dates and perpendicular baselines at scene centre. $B_{\perp}$ The perpendicular baseline is relative to the first image acquisition on 3 October 2014.

\begin{tabular}{llll}
\hline Date & $\mathrm{B}_{\perp}(\mathrm{m})$ & Date & $\mathrm{B}_{\perp}(\mathrm{m})$ \\
\hline 3 October 2014 & 0 & 31 January 2015 & 88 \\
15 October 2014 & -5 & 12 February 2015 & -204 \\
27 October 2014 & 66 & 24 February 2015 & -78 \\
8 November 2014 & 51 & 8 March 2015 & 77 \\
2 December 2014 & 43 & 20 March 2015 & 67 \\
14 December 2014 & 96 & 1 April 2015 & -52 \\
26 December 2014 & 53 & 13 April 2015 & -47 \\
7 January 2015 & 79 & 25 April 2015 & -71 \\
19 January 2015 & 50 & 7 May 2015 & 138 \\
\hline
\end{tabular}

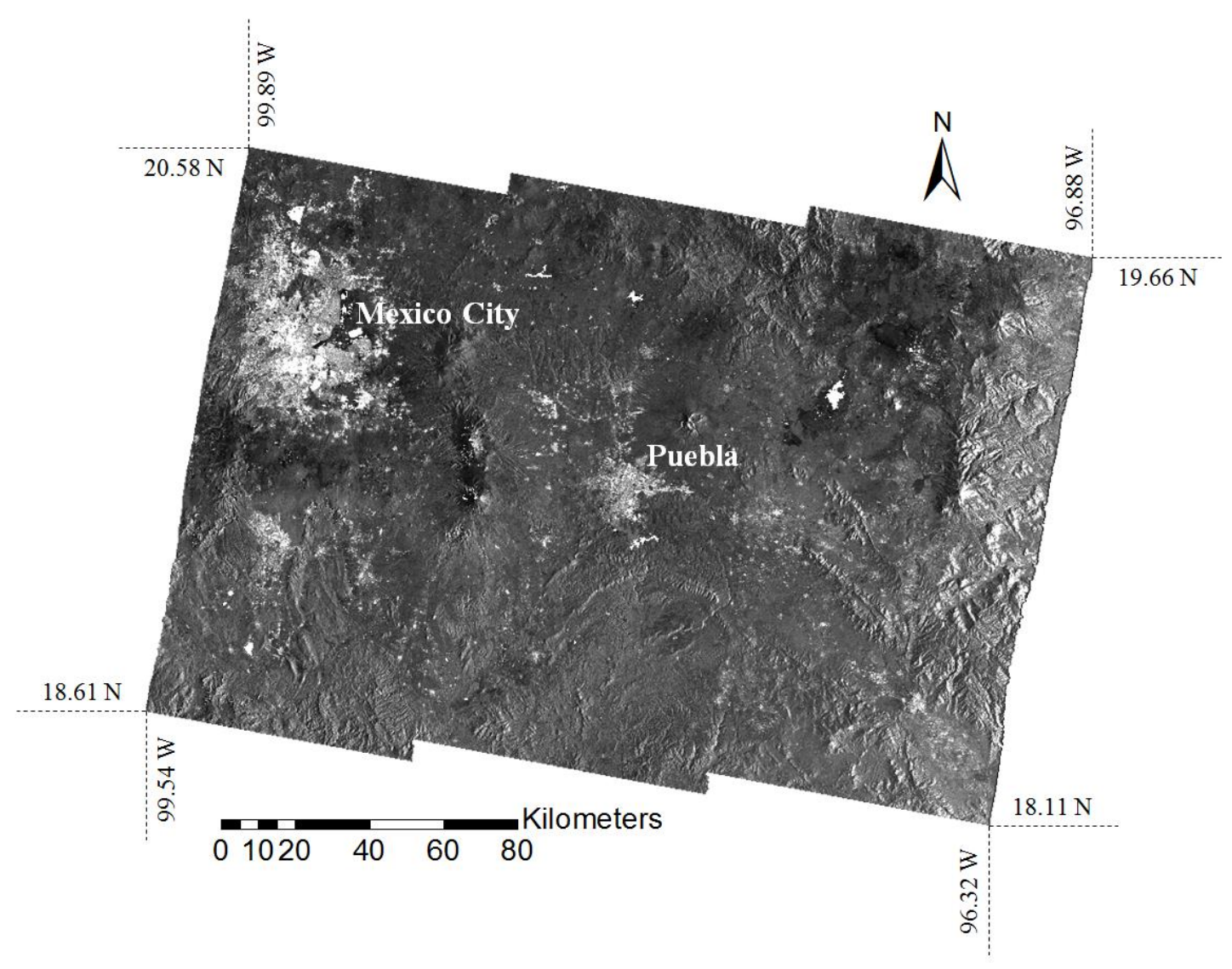

Figure 5. The orthorectified Sentinel-1 amplitude image from 3 October 2014. Mexico City can be clearly seen in the upper left of the image (far range) with the much smaller city of Puebla in the centre. 


\subsection{Image Coregistration and Resampling}

Following the deburst and merge of the 18 slant range SLC images, it was necessary to coregister them to a common slant-range coordinate system. The Sentinel-1 image of 3 October 2014 was taken to be the master and the remaining 17 slave images were separately coregistered to the master, the output being 18 images in the master coordinate system. In this step, only the amplitude data was used for matching and a fast Fourier transform (FFT) coregistration method was utilized (Guizar-Sicairos et al., 2008). The desired coregistration precision was set to 0.001 pixels but accuracy could not be estimated due to the absence of ground control.

\subsection{Generation of the Differential Interferograms}

Differential interferograms were formed for short orbital baseline pairs of coregistered images, following the SBAS method as described by Berardino et al. (2002). All pairs formed had a perpendicular baseline of no greater than $250 \mathrm{~m}$. This small baseline threshold allows maximization of spatial coherence and reduces the phase contribution due to DEM errors (Yan et al., 2012). No threshold was imposed on the temporal baselines, due to the relatively short period of observation covered by the 18 IW scenes (i.e. only 7 months).

A graph of the perpendicular baseline and the time of each acquisition, both relative to the master image, is shown in figure 6. Pairs corresponding to the baseline threshold are shown by the straight lines. The total number of interferograms generated was 143 , corresponding to over $90 \%$ of the possible pair combinations of the 18 scenes, and the average temporal baseline of the interferograms was approximately 82 days. Thanks to the narrow orbital tube of only $100 \mathrm{~m}$ in radius currently being guaranteed for Sentinel-1A, only the scene acquired on 12 February 2015 appeared less connected to the network.

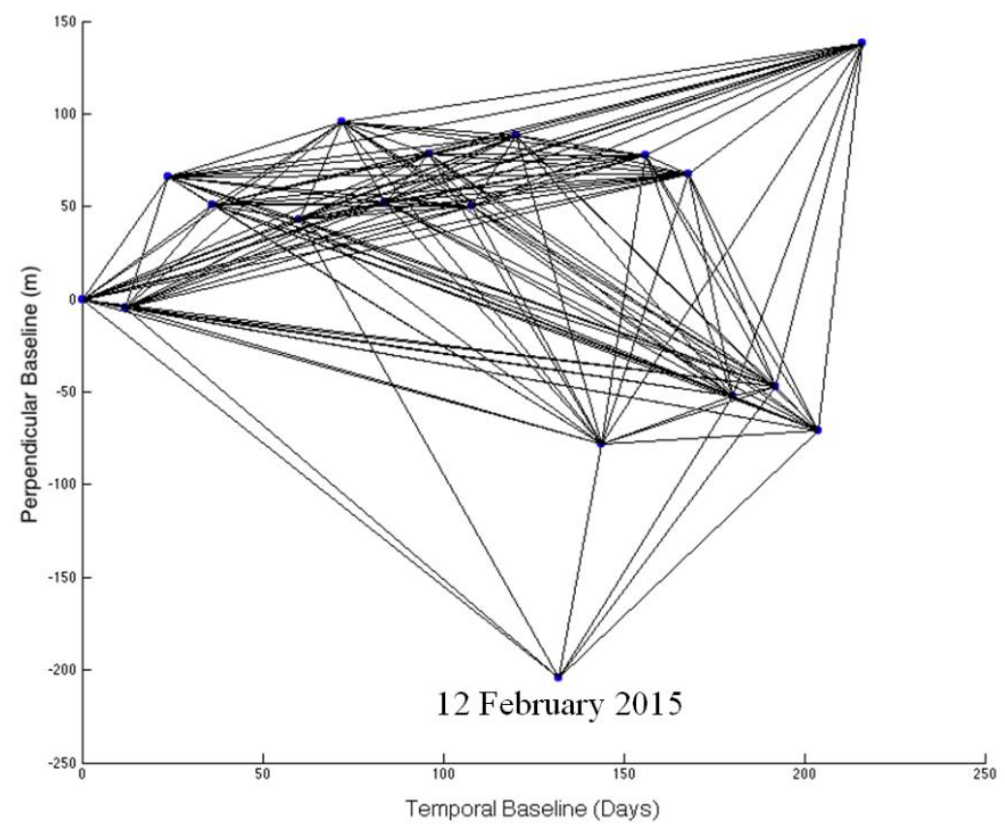

Figure 6. Graph of perpendicular orbital baseline and time relative to the master image on 3 October 2014. Interferogram pairs are indicated by the straight lines linking two images. 
The interferograms formed between the small baseline pairs were then multilooked by a factor of 6 and 30 pixels in azimuth and range directions, respectively. Following the pixel spacing parameters from table1, the resulting multi-looked pixels have an approximate size of $70 \mathrm{~m} \times 85 \mathrm{~m}$ in the slant range and azimuth directions, corresponding to $\sim 115 \mathrm{~m} \times 85 \mathrm{~m}$ in ground range resolution at scene center (assuming an incidence angle of $37.5^{\circ}$ ). The complex coherence was estimated for each $6 \times 30$ window and applied during the multi-looking so that each coherence measure is independent of its neighbours. Differential interferograms were then derived by subtracting the phase from a simulated interferogram based upon a digital elevation model (DEM) obtained from the Shuttle Radar Topography Mission (SRTM) (Farr et al., 2007) and the orbit state vectors provided with the IW products, assumed to be restituted with an accuracy of $<10 \mathrm{~cm}$ (ESA, 2015b).

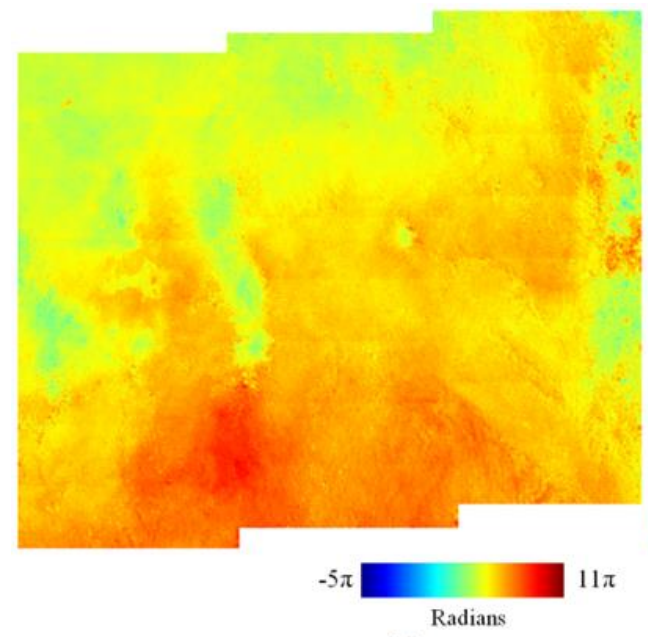

(a)

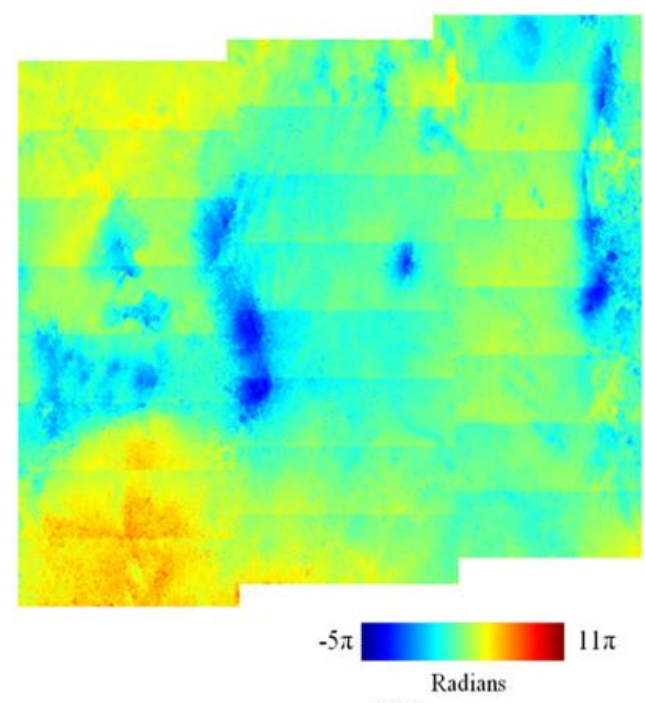

(c)

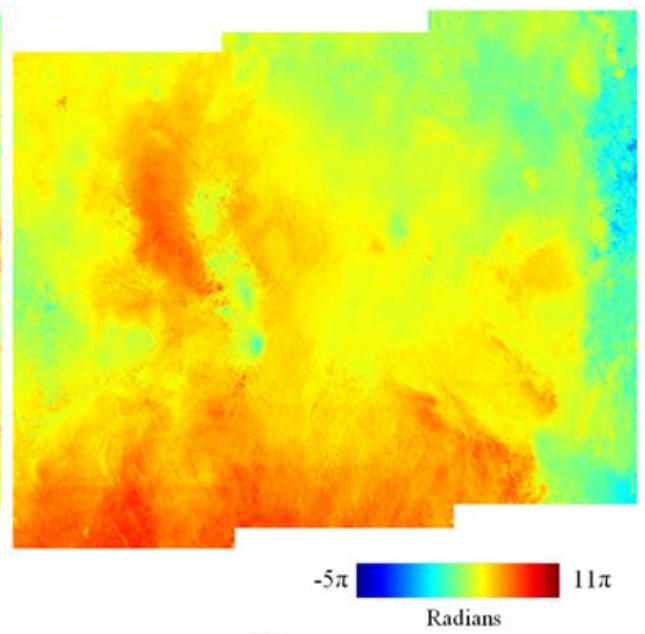

(b)

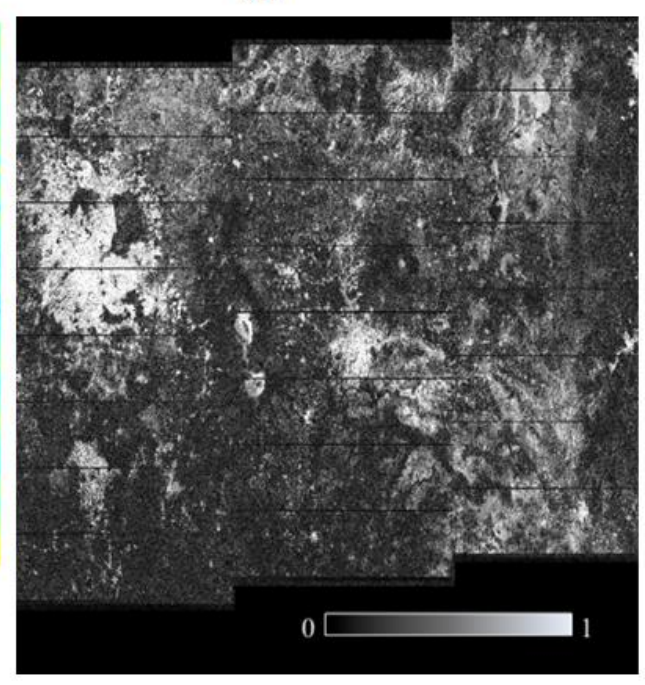

(d)

Figure 7. (a) and (b) are example multi-looked unwrapped differential interferograms exhibiting only very small phase ramp anomalies (19 January - 24 February and 12 February - 24 February pairs, respectively) whereas in $(c)$ these are more obvious (8 November - 31 January pair). (d) demonstrates incoherence at burst edges on the coherence map (horizontal lines) of the 8 November -31 January pair. 
The quality of the differential interferograms was generally very good, with excellent coherence (average greater than 0.25 ) in the many, short temporal baseline, pairs (Figure 7a-b). However, phase ramps due to the imprecision of the coregistration were present in some of them, an example of which is shown in figure $7 \mathrm{c}$ where the resulting phase discontinuity at burst boundaries is clear (shown in the unwrapped differential interferogram). Based on our analysis, the phase ramps range between -5 and +5 radians and are random (Gaussian, mean zero) in nature, therefore the effect is cancelled out during the estimation of velocity. The sensitivity of the ISBAS processing to the phase ramps depends only upon the number of interferograms used, For example, if we assume that the phase ramp has a maximum standard deviation of 1.67 radians (taking 5 radians as the $3 \sigma$ cut-off), the impact on the analysis when using 143 interferograms will be $1.67 / \sqrt{143}$ which gives 0.14 radians standard deviation. In this case, this does result in a higher velocity error, of approximately $0.6 \mathrm{~mm} /$ year in magnitude. In terms of the velocities derived below this is negligible but must be considered if analyzing velocities of a smaller magnitude.

An additional phase discontinuity between sub-swaths was possible due to the difference in the elevation antenna pattern of scenes processed before and after March 2015, due to the correction in the instrument processing facility that was applied to data processed after March 2015 (Miranda, 2015). However, this error was not obvious in any of the interferograms generated here and so a correction for this effect was not applied. There were additional problems encountered with low coherence at the boundaries of the bursts, although these features were not common to all interferograms. Examples of these are further illustrated in figure $7 \mathrm{~d}$ where the burst boundaries are clearly visible. Due to their random nature, however, these phase ramps did not affect the spatial continuity of the estimated ground motion (other than by slightly reducing the density of results at burst boundaries), as discussed in section 7.

\subsection{ISBAS Processing and Phase Unwrapping}

To select the most suitable pixels for the time-series analysis and for the calculation of the LOS velocity of each pixel, we utilised the ISBAS algorithm described in Sowter et al. (2013), Bateson et al. (2015) and Cigna et al. (2014), using 50 as the number of best coherence interferograms threshold and 0.25 as the coherence threshold. The first threshold is an indicator of the minimum number of interferograms that may be used to calculate the velocity and the coherence threshold is used to determine over which pixels velocity may be calculated.

Phase unwrapping of the 143 interferograms was conducted using a reference pixel located in a stable area in the city itself, based on the results from previous publications, i.e. by Osmanoğlu et al. (2011), Yan et al. (2012), ESA (2014b), and ESA (2014d). We used the Statistical-cost Network-flow Algorithm for Phase Unwrapping (SNAPHU) program by Chen and Zebker (2001) to individually unwrap coherent pixels within each interferogram. Following a successful unwrapping process, linear velocity and height error for the selected coherent pixels were computed using a regression analysis. As mentioned above, the resulting map of velocities covered $68 \%$ of the entire wide area product (Figure $8 \mathrm{a}$ ).

The phase discontinuities at burst edges are often larger than $\pi$ radians, which would normally result in a phase ambiguity. This would certainly be a major problem with this approach if unwrapping a single swath. However, as three swaths have been 
mosaicked together to form the full scene, there are additional constraints to the unwrapping from swath-to-swath that appear to link adjacent bursts together and produce a more continuous surface. This is apparent in figure $7 \mathrm{a}-\mathrm{c}$ where the unwrapping process does not appear to have propagated any ambiguity errors from the burst edges across the scene, as could be expected. In this case, unwrapping the whole, mosaicked, scene has actually helped the unwrapping process but a consequence of this is that, if the method was to be applied to a subset of the image, phase unwrapping may not work as well and is best avoided.

Pixel velocities and height corrections were generated using a least-squares regression analysis of the unwrapped phases. Each pixel was geolocated using a range-Doppler algorithm that uses the restituted orbit state vectors from the product header and topographic heights from the SRTM DEM, with the height corrections applied. The geolocation accuracy of Sentinel-1 data is of the order of only a few metres (Schubert et al., 2015) which is much less than the pixel size of $\sim 90 \mathrm{~m}$. Therefore, no additional ground control was used for geolocation.

\section{Sentinel-1 ISBAS Results and Discussions}

\subsection{Observed velocities}

The resulting map of velocities from the ISBAS processing, which covers the complete IW scene, is shown in figure 8a along with a map of the standard error, output from the least squares covariance analysis used to derive the velocities, for each pixel in figure $8 \mathrm{~b}$. As may be seen, the image demonstrates very little motion (the average velocity is less than $\pm 0.24 \mathrm{~cm} /$ year) except in the metropolitan area of Mexico City, where there is substantial subsidence of around $-24 \mathrm{~cm} /$ year in the LOS of the satellite. A detail of the city area is shown in figure 9.

As can be seen from both figures $8 \mathrm{a}$ and $9 \mathrm{c}$, there is neither any noticeable effect caused by the incoherence between bursts nor by the phase ramps on the velocities despite their visible effects in some of the differential interferograms (see section 6 above). The incoherent jumps also do not appear on the amplitude images, therefore there is no perceived mosaicking error. As the phase ramps are related to the coregistration accuracy, the magnitude is likely to be random from one interferogram to another, with mean zero, thereby having a decreasing influence on the velocity as the number of interferograms increases. An implication of this is that multiple master InSAR techniques such as ISBAS, where large numbers of interferograms are generated, may not need to implement high-precision coregistration methods to mitigate for the phase ramp effect. However, a consequence of this may be increased standard errors, in comparison to stripmap products. 

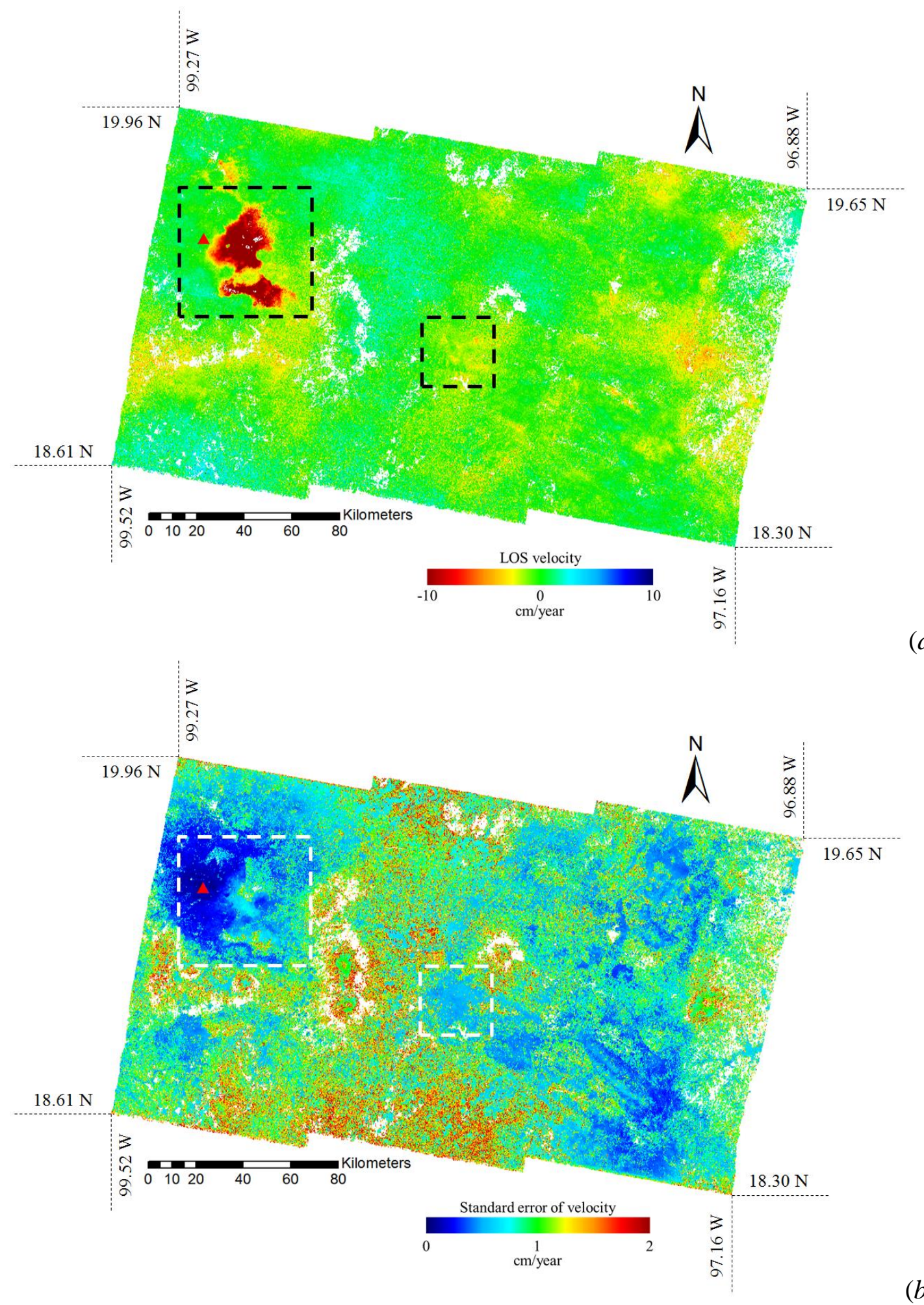

(a)

(b)

Figure 8. ISBAS results for the complete scene. The red triangle shows the location of the reference point used for phase unwrapping. ( $a$ ) is the LOS velocity map, and $(b)$ standard error of the LOS velocities. The dashed boxes are the extents of the details shown in figure 9 for Mexico City and figure 10 for Puebla. 
As may be seen in figure 9c, there is a thin line of missing velocities at the burst boundaries. Indeed this is exactly one multilooked-pixel wide and is due to the phase ramp anomalies that can be clearly seen in figure 7 . When multilooked pixels straddle the burst boundary, they uniquely include this phase ramp anomaly, significantly reducing the complex correlation coefficient used to calculate the coherence. Hence, these pixels consistently do not meet the criteria for velocity calculations and are missing from the final coverage. These missing pixels did not interrupt the spatial distribution of any of the observed deformations, suggesting that these missing lines did not affect the capability of the method for wide-area analysis of ground motion.

The estimated LOS velocities from our processing range between $-24.84 \mathrm{~cm}$ and $+9.24 \mathrm{~cm} /$ year with an average value of $-0.48 \mathrm{~cm} /$ year across the whole scene. The respective standard errors fall between $0.24 \mathrm{~cm} /$ year and $3.24 \mathrm{~cm} /$ year, with an average of $0.94 \mathrm{~cm} /$ year. As expected, smaller standard errors are observed in urban compared to rural areas as supported by the cross-section profiles in figure $10 \mathrm{e}$ and 10f, with most of the values being less than $0.6 \mathrm{~cm} /$ year due to the high number of interferograms used per pixel (Cigna et al., 2014). Conversely, higher standard errors are found in non-urban areas, for instance north of Ciudad Nezahualcóyotl and in Chalco, where standard errors are 0.6 to $1.2 \mathrm{~cm} /$ year. 


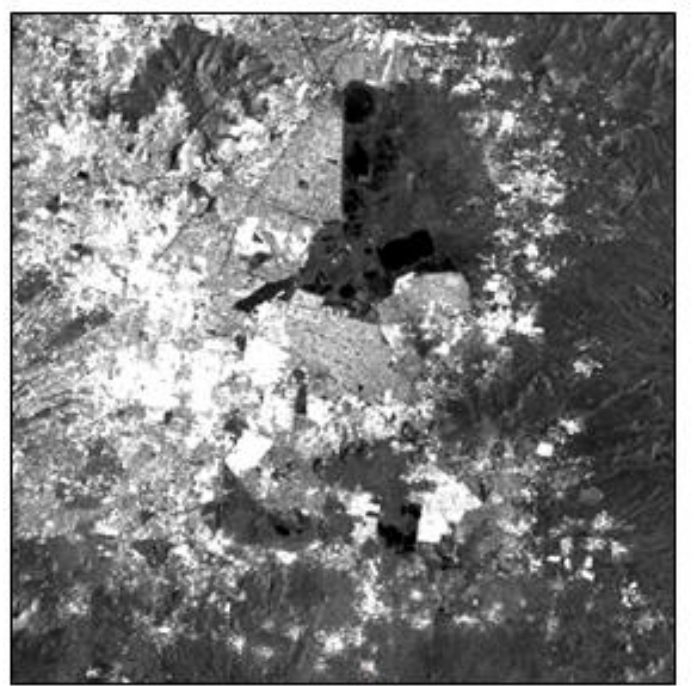

(a)

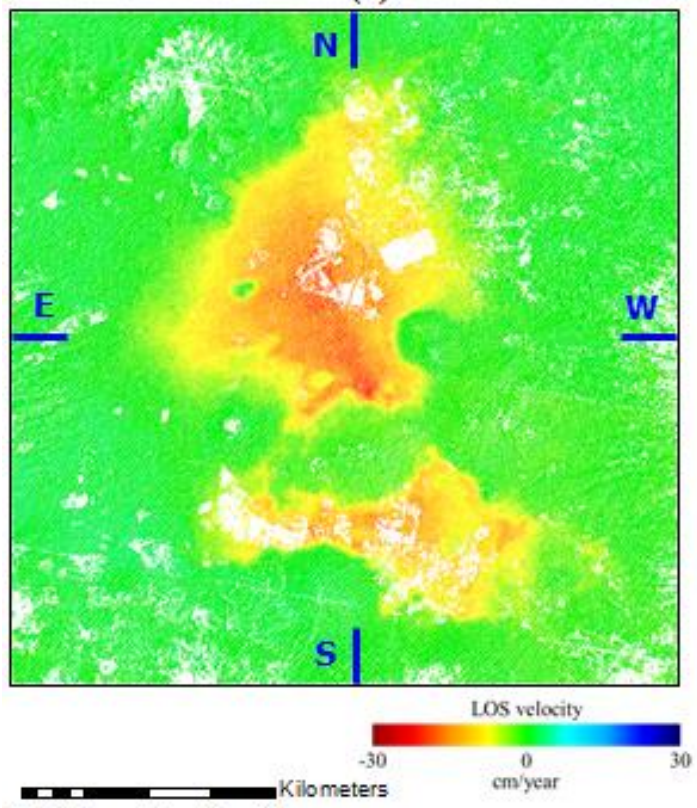

(c)

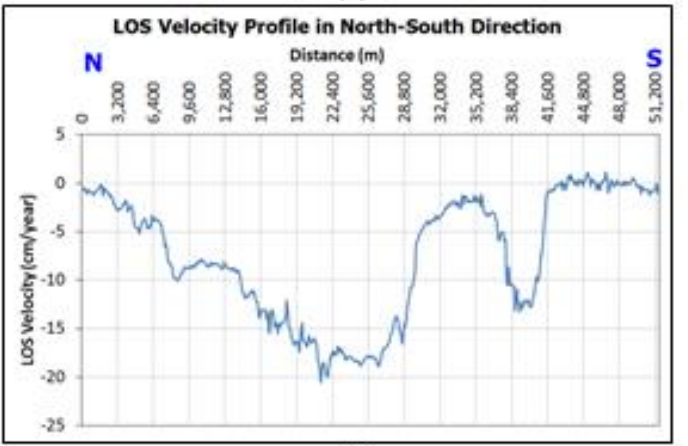

(e)

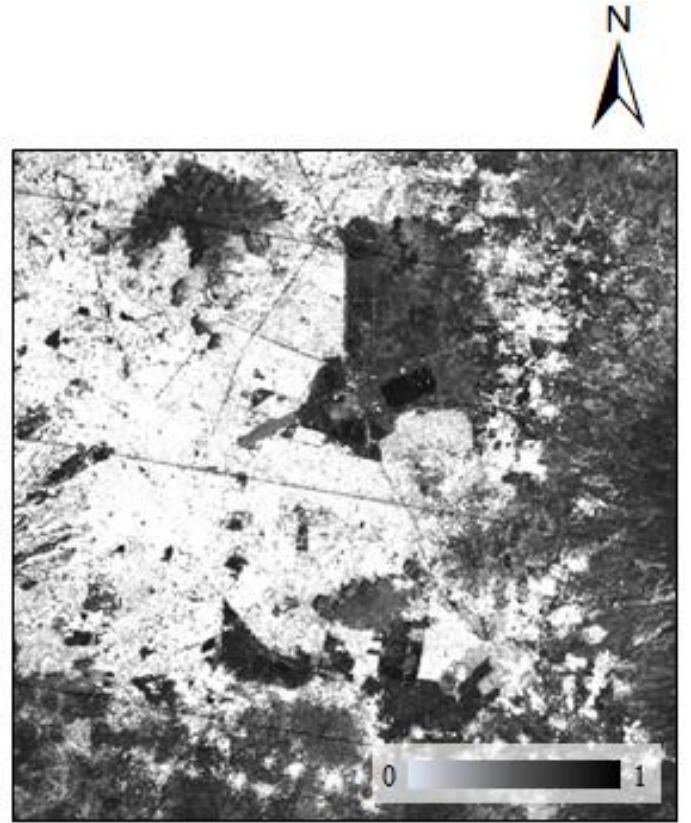

(b)

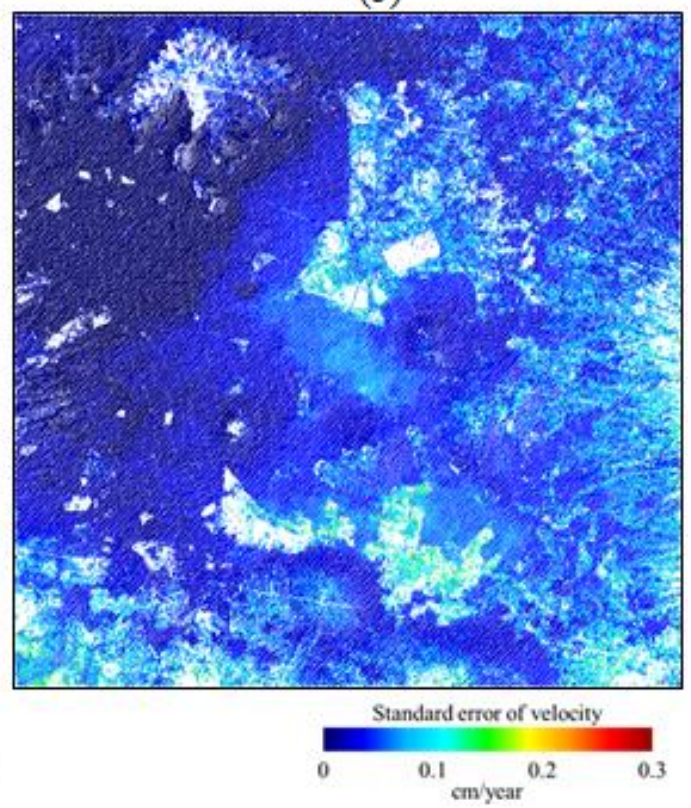

(d)

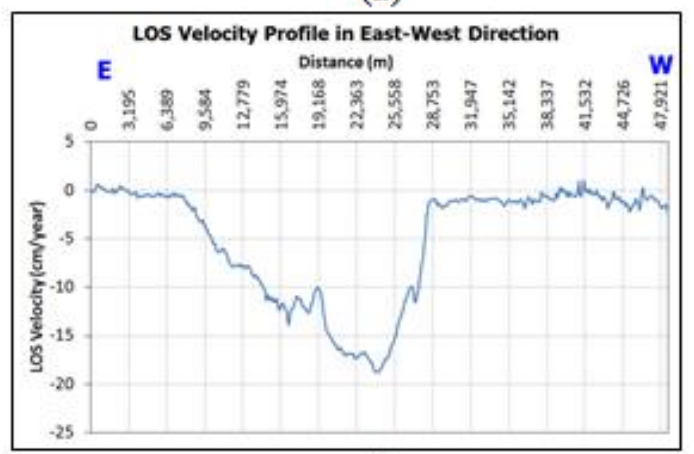

$(f)$

Figure 9. ISBAS results for Mexico City. (a) is the average amplitude image; $(b)$ the average coherence; $(c)$ is the LOS velocity map; $(d)$ the standard error of the LOS velocities; (e) LOS velocity profile in North-South direction; and $(f)$ LOS velocity profile in East-West direction. 


\subsection{Comparison with historical C-band and L-band PSI and SBAS studies}

We compared the ISBAS subsidence rates for October 2014 to May 2015 with other multi-temporal DInSAR studies using ENVISAT and L-band ALOS imagery covering the metropolitan area during the 2000s.

Cabral-Cano et al. (2010) and Cigna et al. (2011) focussed on the south-eastern sector of the metropolitan area using a PSI approach to process ENVISAT imagery for the period 2004-2006. These studies observed approximately -10 to $-15 \mathrm{~cm} /$ year in Chalco and Iztapalapa and found LOS rates higher than $-28 \mathrm{~cm} /$ year (i.e. over -30 $\mathrm{cm} /$ year vertical rates) in the southern sector of Ciudad Nezahualcóyotl. SBAS and PSI studies by López-Quiroz et al. (2009), Yan et al. (2012) confirmed that up to -38 $\mathrm{cm} /$ year vertical rates in Ciudad Nezahualcóyotl and Chalco were observed with longer ENVISAT data stacks covering the period 2002-2007.

In Ciudad Nezahualcóyotl, the Sentinel-1 ISBAS results indicate LOS rates of -18 to over $-24 \mathrm{~cm} /$ year in 2014-2015. Assuming that the rates estimated by the 7 monthlong Sentinel-1 stack are representative of the average annual rates, the movement is equivalent to about $\sim-24 \mathrm{~cm} /$ year along the Sentinel-1 LOS. Accounting for the value of the latter at the location of Ciudad Nezahualcóyotl (i.e. $\sim 43^{\circ}$, being Mexico City depicted in the middle of IW3, in the far range), the reprojected annual rate along the vertical direction equals $-33 \mathrm{~cm} /$ year for 2014-2015. Hence the ISBAS velocity perfectly aligns with the historical ENVISAT rates in 2004-2006 and 2002-2007.

Another ENVISAT PSI analysis looking at subsidence affecting the north-western sector of the metropolitan area in 2004-2006 (Osmanoğlu et al., 2011) found LOS rates of $\sim-25 \mathrm{~cm} /$ year (i.e. $-27 \mathrm{~cm} /$ year vertical rates) east of the city airport. In the same area, the Sentinel-1 ISBAS results show rates of $\sim-18 \mathrm{~cm} /$ year (i.e. equivalent to $\sim-25 \mathrm{~cm} /$ year vertical rates), confirming that in 2014-2015 the magnitude of land motion for this area too is similar to the historical rates observed during the 2000s. The latter are also confirmed by the -22 to $-26 \mathrm{~cm} /$ year vertical rates measured in 2005-2010 by the MPAA and MMX1 GPS stations nearby (e.g. Cabral-Cano et al., 2010).

A recent wide-area InSAR survey of central Mexico was undertaken by Chaussard et al. (2014). Over Mexico City, the study applied an SBAS algorithm to 19 ascending and 5 descending mode ALOS PALSAR data gathered between 2007 and 2011 which, with an L-band frequency, are generally more suitable for surveys of rural areas than C-band as they suffer less decorrelation due to vegetation. In Ciudad Nezahualcóyotl, ALOS rates for 2007-2011 indicate around $-30 \mathrm{~cm} /$ year of vertical motion. Outside the city, north of the Nabor Carrillo lake, the ALOS study resulted in similar results to the Sentinel-1 ISBAS method, both showing vertical subsidence rates of $\sim-15 \mathrm{~cm} /$ year. Nevertheless, even with a similar number of input scenes (i.e. 19 ALOS vs. 18 Sentinel-1), it can be observed that the coverage of the Sentinel-1 ISBAS analysis provided a much more complete land motion picture than that generated by the L-band SBAS analysis as presented in the Chaussard et al. (2014).

Additionally, some patches of deformation linked to industrial activity were also detected in the ALOS SBAS study around the city of Puebla with a maximum rate of approximately -3.6 to $-4.8 \mathrm{~cm} /$ year which were not detected by this Sentinel-1 ISBAS 
study. Visual inspection of those Sentinel-1 differential interferograms with large temporal baselines (figure 10) did not show any clear persistent nor significant phase changes in Puebla that could easily be distinguished from atmospheric delay. This may indicate that the significant land motion of the order observed by ALOS was not present during the 2014-2015 period of Sentinel-1 observations, or it may also indicate that the current amplitude of deformation was too small to be detected in the 12 to 216 day range of temporal baselines used for this ISBAS analysis.

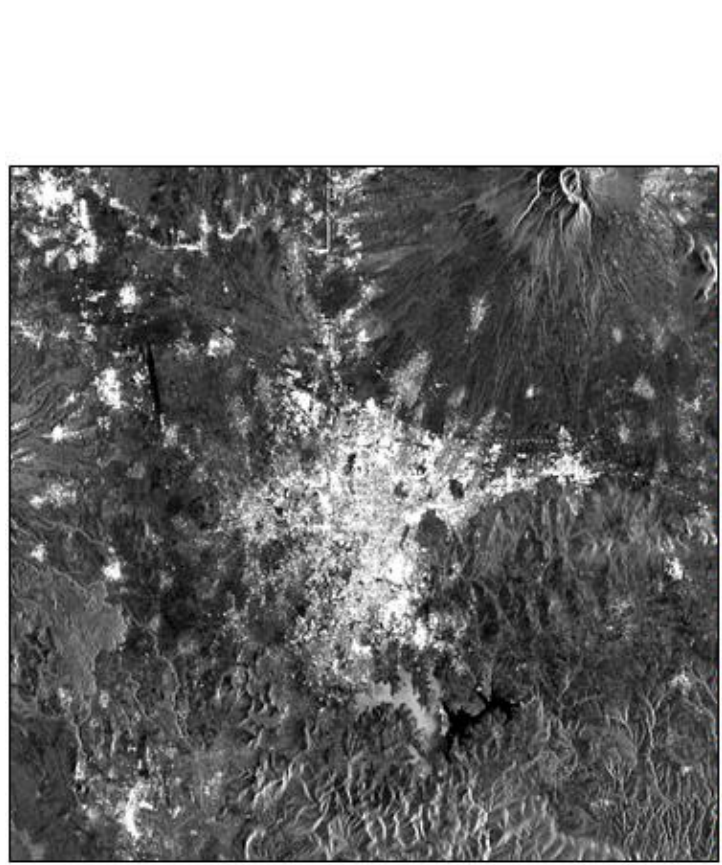

(a)

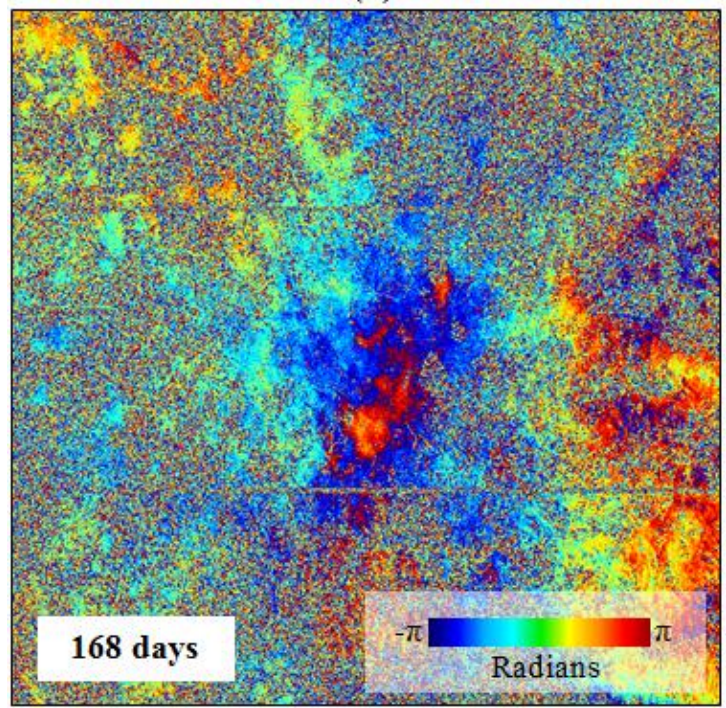

$024 \quad 8 \quad 1216$
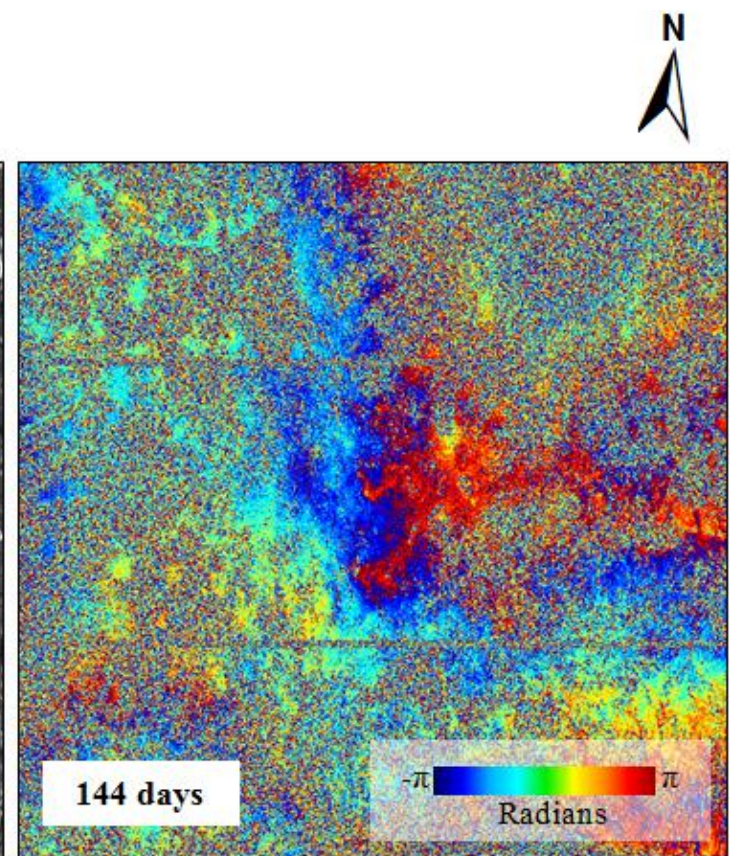

(b)

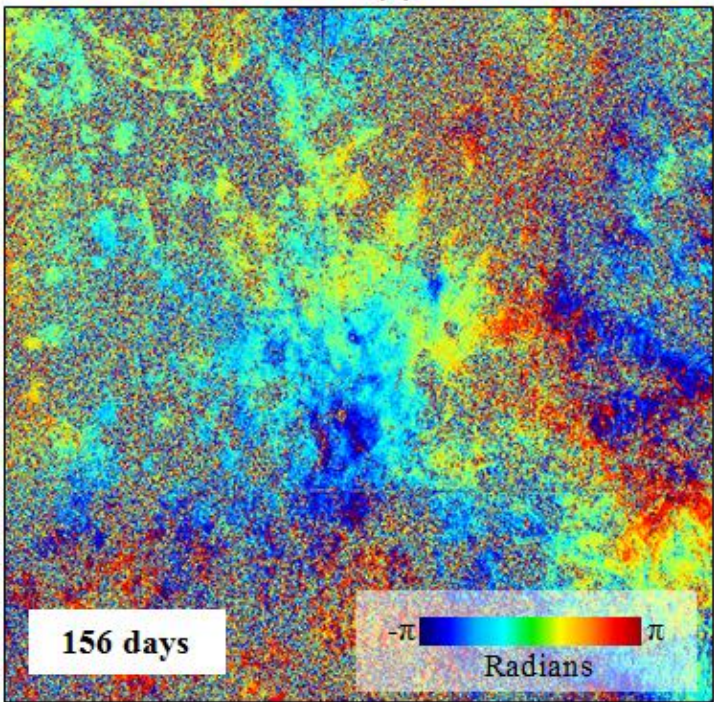

(d)

Figure 10. (a) Average amplitude image of the city of Puebla; $(b-d)$ three long temporal baseline interferograms of Puebla indicating no clear large and persistent displacement over the period of Sentinel-1 observations (3 October 2014 and 24 February 2015 with $\mathrm{B}_{\perp}=-77.906,3$ October 2014 and 20 March 2015 with $\mathrm{B}_{\perp}$ $=67.215$ and 15 October 2014 and 20 March 2015 with $B_{\perp}=72.153$ pairs respectively). 


\subsection{Comparison with other Sentinel-1A and RADARSAT-2 TOPS studies}

We also compared our Sentinel-1 LOS velocity map of Mexico City to those published by:

- ESA (2014d), Geudtner (2014) and Lanari et al. (2015), generated from 11 RADARSAT-2 Progressive ScanSAR Narrow B mode, TOPS-like images with 24 day repeat cycle acquired between 4 April and 30 November 2013;

- ESA (2014b), generated by ESA's SEOM Programme InSARap project from 5 Sentinel-1 images acquired between 3 October and 2 December 2014;

- Wegmüller et al. (2015), generated using 12 Sentinel-1A descending mode scenes acquired between 3 October 2014 and 8 March 2015;

- Osmanoğlu et al. (2015), generated using 38 ENVISAT ASAR descending mode scenes acquired between November 2002 and March 2007;

- Prats-Iraola et al. (2015), used 4 different stacks of 12-13 Sentinel-1A scenes each acquired in ascending and descending mode between 8 October 2014 and 16 March 2015.

Based on visual comparison, we found reasonable agreement between the ISBAS results and all the above studies in terms of both the magnitude of the deformation rate and the spatial extent. Only small differences in the range of $\pm 5 \mathrm{~cm} /$ year can be observed in the velocity results provided by the different studies. These are, however, mostly explained by the differences in the observation periods and their length (and presence of atmospheric phase components in shorter data stacks), and partly by the employed processing methods (e.g., SBAS or PSI, low- or high-resolution).

\section{Conclusion}

Sentinel-1 offers a huge potential for the support of future monitoring of land surface deformation. However, IW products are in a very different format to the stripmap data that has been commonly used for InSAR surveys in the past. SLC products from missions such as ERS, ENVISAT, TerraSAR-X and COSMO-SkyMed data can nominally be processed using the same basic DInSAR algorithm but the debursting, merging and deramping processes, and the requirement for high-precision coregistration that need to be applied to Sentinel-1 IW SLC products make these data a very different proposition for the scientific and operational InSAR community.

In this paper we have demonstrated that these problems do not preclude the generation of wide-area maps of deformation from a stack of Sentinel-1 data. A 250 $\mathrm{km}$ wide area that includes the metropolitan area of Mexico City has been surveyed using 18 IW SLC products freely available from the Sentinel-1 Scientific Data Hub (ESA 2014c). An existing DInSAR time-series technique, ISBAS, has been adapted to process Sentinel-1 data with targeted changes necessary to address debursting, merging and deramping. 
A map of LOS velocities for the complete scene was produced that agrees in magnitude and extent with the results of previous DInSAR surveys that have also used similar DInSAR methods both exploiting historical ERS, JERS and ENVISAT data for the 1990s and 2000s, and more recent imagery acquired by ALOS in 2007-2011, RADARSAT-2 in 2013 and Sentinel-1 in 2014-2015.

Although no high-precision co-registration method was applied in this study to reduce the effect of phase ramps, there appears to be no residual effect upon the velocities and no interruption in the spatial distribution of the observed deformation, other than a very slight reduction in the density of ISBAS results at burst boundaries. We postulate that this is likely due to the random nature of the effect, reduced by averaging over the large numbers of interferograms used by the ISBAS method.

The accuracy of the ISBAS velocity estimates based on the stack of 18 IW images was, on average, better than $1.2 \mathrm{~cm} /$ year across most of the scene. We fully expect that the precision of the measurements will be improved when a larger number of image acquisitions over this area become available in the coming months and that this will also allow a commensurate improvement in pixel coverage. We noted that the estimation of linear velocity and height correction for DEM could be affected by undue weight in epochs with large number of input interferograms as the result from using more than independent observations; therefore, we will further investigate this effect in our future work.

\section{Acknowledgments}

The Sentinel-1 IW SLC data used in this paper were provided by the European Space Agency through the Sentinel-1 Scientific Data Hub (ESA 2014c). The SRTM $90 \mathrm{~m}$ DEM V4 was made available by CGIAR-CSI (http://srtm.csi.cgiar.org). F. Cigna publishes with the permission of the Executive Director of the British Geological Survey (BGS), Natural Environment Research Council (NERC).

\section{References}

Attema, E., Cafforio, C., Gottwald, M., Guccione, P., Monti Guarnieri, A., Rocca, F. and Snoeij, P., 2010. "Flexible Dynamic Block Adaptive Quantization for Sentinel-1 SAR Missions." IEEE Geoscience and Remote Sensing Letters, 7(October), pp.766-770.

Bateson, L., Cigna, F., Boon, D. and Sowter, A., 2015. "The Application of the Intermittent SBAS (ISBAS) InSAR Method to the South Wales Coalfield, UK." International Journal of Applied Earth Observation and Geoinformation, 34(2015), pp.249-257. doi:10.1016/j.jag.2014.08.018.

Berardino, P., Fornaro, G., Lanari, R. and Sansosti, E., 2002. "A New Algorithm for Surface Deformation Monitoring Based on Small Baseline Differential SAR Interferograms." IEEE Transactions on Geoscience and Remote Sensing, 40(11), pp.2375-2383.

Cabral-Cano, E., Dixon, T.H., Miralles-Wilhelm, F., Díaz-Molina, O., SánchezZamora, O. and Carande, R.E., 2008. "Space Geodetic Imaging of Rapid Ground 
Subsidence in Mexico City." Bulletin of the Geological Society of America, 120(December), pp.1556-1566.

Cabral-Cano E., Osmanoğlu B., Dixon T., Wdowinski S., Demets C., Cigna F., DíazMolina O., 2010, "Subsidence and fault hazard maps using PSInSAR and permanent GPS networks in central Mexico." In: D. Carreón-Freyre et al. (ed.), Land subsidence, associated hazards and the role of natural resources development, Hydrological Sciences Journal, Red Book Series. IAHS Press, 255259.

Cabral-Cano E., Solano-Rojas D., Oliver-Cabrera T., Wdowinski S., Chaussard E., Salazar-Tlaczani L., Cigna F., DeMets C., Pacheco-Martinez J., 2015. "Subsidence and associated shallow faulting hazard assessment in central Mexico using InSAR and GPS." FRINGE 2015, 23-27 March 2015, ESAESRIN, Frascati, Italy. Available at: http://seom.esa.int/fringe2015/files/presentation234.pdf

Chaussard, E., Wdowinski, S., Cabral-Cano, E. and Amelung, F. 2014. Land subsidence in central Mexico detected by ALOS InSAR time-series. Remote Sensing of Environment, 140, 94-106.Chen, C.W. and Zebker, H.A., 2002. "Phase Unwrapping for Large SAR Interferograms: Statistical Segmentation and Generalized Network Models." IEEE Transactions on Geoscience and Remote Sensing, 40, pp.1709-1719.

Chen, C. W. and Zebker, H. A., 2001. Two-dimensional phase unwrapping with use of statistical models for cost functions in nonlinear optimization, J. Opt. Soc. Amer. A, vol. 18, pp. 338-351.

Cigna, F., Sowter, A., Jordan, C.J., \& Rawlins, B.G., 2014, "Intermittent Small Baseline Subset (ISBAS) monitoring of land covers unfavourable for conventional C-band InSAR: proof-of-concept for peatland environments in North Wales, UK." In Proc. SPIE 9243, SAR Image Analysis, Modeling, and Techniques XIV, 22 October 2014, 924305. Amsterdam, The Netherlands, doi: 10.1117/12.2067604.

Cigna F., Cabral-Cano E., Osmanoğlu B., Dixon T.H., Wdowinski S., 2011, "Detecting subsidence-induced faulting in Mexican urban areas by means of Persistent Scatterer Interferometry and subsidence horizontal gradient mapping." IEEE Int. Geosci. \& Remote Sensing Symp., IGARSS 2011, 2125-2128. doi: 10.1109/IGARSS.2011.6049585

Crosetto, M., Monserrat, O., Iglesias, R. and Crippa, B., 2010, "Persistent Scatterer Interferometry: Potential, Limits and Initial C- and X-band Comparison," Photogrammetric Engineering and Remote Sensing, Vol. 76, No. 9, pp10611069

De Zan, F., Guarnieri, A. M. and Rocca, F., 2008. "Advances in SAR Interferometry for Sentinel-1 with TOPS.” 2008 IEEE Radar Conference, RADAR 2008. pp. 16. 
De Zan, F., Prats-Iraola, P., Scheiber, R. and Rucci, A., 2014. "Interferometry with TOPS: Coregistration and Azimuth Shifts." EUSAR 2014; 10th European Conference on Synthetic Aperture Radar; Proceedings of. pp. 1-4.

ESA, 2013, "Sentinel-1 User Handbook." European Space Agency. Ref: GMESS1OP-EOPG-TN-13-0001, 1st September 2013.

ESA, 2014a. "Introducing Sentinel-1." European Space Agency. Available at: http://www.esa.int/Our_Activities/Observing_the_Earth/Copernicus/Sentinel1/Introducing_Sentinel-1 [Accessed March 6, 2015].

ESA, 2014b. "Mexico City Subsidence." European Space Agency. Available at: http://www.esa.int/spaceinimages/Images/2014/12/Mexico_City_subsidence [Accessed March 9, 2015].

ESA, 2014c. "Sentinel-1 Scientific Data Hub." European Space Agency. Available at: https://scihub.esa.int/dhus/ [Accessed February 19, 2015].

ESA, 2014d. "Subsidence Mexico City." European Space Agency. Available at: http://www.esa.int/spaceinimages/Images/2014/03/Subsidence_Mexico_City [Accessed March 9, 2015].

ESA, 2015a. "Definition of the TOPS SLC deramping function for products generated by the S-1 IPF." European Space Agency. COPE-GSEG-EOPG-TN-14-0025, Issue 1, Revision 2, 22 April 2015.

ESA, 2015b. "Sentinels POD Service File Format Specifications." European Space Agency. GMES-GSEG-EOPG-FS-10-0075, Issue 1, Revision 16, 27 March 2015.

Farr, T.G., Rosen, P. A., Caro, E., Crippen, R., Duren, R., Hensley, S., Kobrick, M., Paller, M., Rodriguez, E., Roth, L., Seal, D., Shaffer, S., Shimada, J., Umland, J., Werner, M., Oskin, M., Burbank, D. and Alsdorf, D.E., 2007. "The Shuttle Radar Topography Mission.” Reviews of Geophysics, 45, pp.1-43.

Ferretti A., Prati C. and Rocca F., 2001, "Permanent scatterers in SAR interferometry," IEEE Transactions on Geoscience and Remote Sensing, Vol. 39, No.1.pp. $8-20$.

Ferretti, A., Fumagalli, A., Novali, F., Prati, C., Rocca, F. and Rucci, A., 2011. "A New Algorithm for Processing Interferometric Data-Stacks: SqueeSAR." IEEE Transactions on Geoscience and Remote Sensing, 49, pp. 3460-3470.

Figueroa Vega, G.E., 1976. "Subsidence of the City of Mexico; A Historical Review." Proceeding of the Anaheim Symposium. International Association of Hydrological Sciences, pp. 35-38.

Geudtner D. 2014, "Implementation of the TOPS Mode on RADARSAT-2 in Support of the Copernicus Sentinel-1 Mission. RADARSAT-2 TOPS SAR Interferometry (InSAR) Data Stack Acquisitions." Technical Note. Issue 1.0, 25 
February 2015. $14 \quad$ pp. Available at: https://earth.esa.int/documents/10174/134665/S1-TN-ESA-SY0469_RSAT_TOPS_InSAR_Stack_Report

Guizar-Sicairos, M., Thurman, S.T. and Fienup, J.R., 2008, "Efficient subpixel image registration algorithms," Opt. Lett., 33, pp.156-158.

Holzner, J. and Bamler, R., 2002. "Burst-Mode and ScanSAR Interferometry." IEEE Transactions on Geoscience and Remote Sensing, 40(September), pp.1917-1934.

Hooper, A., Zebker, H., Segall, P. and Kampes, B., 2004. "A new method for measuring deformation on volcanoes and other natural terrains using InSAR persistent scatterers." Geophys. Res. Lett, 31 (23), 5.

Hooper, A., 2008. "A multitemporal InSAR method incorporating both persistent scatterer and small baseline approaches." Geophys. Res. Lett., 35 (16).

López-Quiroz, P., Doin, M.P., Tupin, F., Briole, P. and Nicolas, J.M., 2009. "Time Series Analysis of Mexico City Subsidence Constrained by Radar Interferometry." Journal of Applied Geophysics, 69(1), pp.1-15. doi:10.1016/j.jappgeo.2009.02.006.

Lanari R., Berardino P., Bonano M., Casu F., De Luca C., Elefante S., Fusco A., Manunta M., Manzo M., Ojha C., Pepe A., Sansosti E., and Zinno I. 2015. "Sentinel-1 results: SBAS-DInSAR processing chain developments and land subsidence analysis." Proc. IEEE Int. Geosci. \& Remote Sensing Symp., IGARSS 2015, 26-31 July 2015, Milan, Italy. pp. 2836-2839.

Massonnet, D. and Feigl, K.L., 1998, "Radar interferometry and its application to changes in the earth's surface." Reviews of Geophysics, 36(4), pp.441- 500.

Miranda, N., 2015, "Sentinel-1 Instrument Processing Facility: Impact of the Elevation Antenna Pattern Phase Compensation on the Interferometric Phase Preservation," European Space Agency Technical Note ESA-EOPG-CSCOPTN-0004, Issue 1, 22 July 2015.

Osmanoğlu, B., Dixon, T.H., Wdowinski, S., Cabral-Cano, E. and Jiang, Y., 2011. "Mexico City Subsidence Observed with Persistent Scatterer InSAR." International Journal of Applied Earth Observation and Geoinformation, 13(2011), pp.1-12.

Osmanoğlu, B., Sunar, F., Wdowinski, S. and Cabral-Cano, E. 2015. Time series analysis of InSAR data: Methods and trends. ISPRS Journal of Photogrammetry and Remote Sensing.

Prats-Iraola P., Nannini M., Scheiber R., De Zan F., Wollstadt S., Minati F., Vecchioli F., Costantini M., Bucarelli A., Borgstrom S., Walter T., Foumelis M., Desnos Y.-L. 2015, "Investigations with the Sentinel-1 Interferometric Wide Swath 
Mode." FRINGE 2015, 23 and 27 March 2015, ESA-ESRIN, Frascati, Italy. Available at: http://seom.esa.int/fringe2015/files/presentation17.pdf

Rucci, A., Ferretti, A., Monti Guarnieri, A. and Rocca, F., 2012. "Sentinel 1 SAR Interferometry Applications: The Outlook for Sub Millimeter Measurements." Remote Sensing of the Environment, 120, pp.156-163. doi:10.1016/j.rse.2011.09.030.

Scheiber, R. and Moreira, A., 2000. "Coregistration of Interferometric SAR Images using Spectral Diversity." IEEE Transactions on Geoscience and Remote Sensing, 38(September), pp.2179-2191.

Schubert, A., Small, D., Miranda, N., Geudtner, D. and Meier, E., 2015. "Sentinel-1A Product Geolocation Accuracy: Commissioning Phase Results." Remote Sensing, 7, pp. 9431-9449.

Sowter, A., Bateson, L., Strange, P., Ambrose, K. and Syafiudin, M.F., 2013. "DInSAR Estimation of Land Motion using Intermittent Coherence with Application to the South Derbyshire and Leicestershire Coalfields." Remote Sensing Letters, 4(10), pp.979-987.

Strozzi, T., Wegmüller, U., Werner, C.L., Wiesmann, A. and Spreckels, V., 2003. "JERS SAR Interferometry for Land Subsidence Monitoring." IEEE Transactions on Geoscience and Remote Sensing. pp. 1702-1708.

Torres, R., Snoeij, P., Geudtner, D., Bibby, D., Davidson, M., Attema, E., Potin, P., Rommen, B., Floury, N., Brown, M., Traver, I.N., Deghaye, P., Duesmann, B., Rosich, B., Miranda, N., Bruno, C., L'Abbate, M., Croci, R., Pietropaolo, A., et al., 2012. "GMES Sentinel-1 Mission." Remote Sensing of Environment, 120(2012), pp.9-24. doi:10.1016/j.rse.2011.05.028.

Wegmüller U., Werner C., Strozzi T., Wiesmann A., Frey O., and Santoro M., 2015, "Sentinel-1 support in the GAMMA software." FRINGE 2015, 23 and 27 March 2015, ESA-ESRIN, Frascati, Italy. Available at: http://sen3app.fmi.fi/publications/fringe15_wegmuller_software.pdf

Yan, Y., Doin, M.P., López-Quiroz, P., Tupin, F., Fruneau, B., Pinel, V. and Trouvé, E., 2012. "Mexico City Subsidence Measured by InSAR Time Series: Joint Analysis using PS and SBAS Approaches." IEEE Journal of Selected Topics in Applied Earth Observations and Remote Sensing, 5(August), pp.1312-1326. 